\title{
Assessment of Post-traumatic Stress Disorders (PTSD) among Saudi Mothers Having a Child Newly Diagnosed with Cancer
}

\author{
Amal Ibrahim Khalil ${ }^{1,2, *}$, Mawdah Hasan Alshanqiti ${ }^{2}$, Amani Homeed AlHarbi ${ }^{2}$ \\ ${ }^{1}$ Faculty of Nursing, Menoufia University, Egypt \\ ${ }^{2}$ College of Nursing, King Saud bin Abdul-Aziz University for Health Sciences, Saudi Arabia
}

Copyright $\bigcirc 2017$ by authors, all rights reserved. Authors agree that this article remains permanently open access under the terms of the Creative Commons Attribution License 4.0 International License

\begin{abstract}
Background: Posttraumatic Stress Disorder (PTSD) is a psychiatric disorder strike people who have experienced or witnessed a traumatic event. Parents' of children with cancer are at risk of PTSD. The aim of the study is to assess the posttraumatic stress disorder symptoms among Saudi mothers who have a child newly diagnosed with cancer. Methodology: A descriptive exploratory design was used with a convenient sample of 110 Saudi mothers. Mothers were recruited from pediatric oncology (Ward 11) at King Khalid National Guard Hospital (KKNGH), Jeddah. Mothers completed a questionnaire of self-report PTSD Checklist (PCL-C) The PTSD severity was determined by totaling the 20 PDS- 5 as the higher the score the more the severity of PTSD. Results: the results revealed that the mean age of children and mothers was $(4.43 \pm$ SD 3.6$)$ and (37.6 \pm SD9.3) respectively. More than half(57.2\%) of mothers experienced with shock at the time of diagnosis. More than one-third (32.7\%) meet the criteria of PTSD and severity of symptoms ranged from mild to very severe as (44.5\%) have mild symptoms $(14.5 \%)$, moderate $(17.3 \%)$ severe compared by (6.4) experienced very severe symptoms of PTSD. Furthermore, there was a significant correlation between the severity of PTSD with the number of children, the age of parents, gender, literacy and economic state $(\mathrm{P}=$ 0.001). Conclusion and recommendation: the study concluded the presence of PTSD symptoms among participants of the current study. Additionally, factors such as age, sex, the number of children, educational state and economic state of the family can influence the severity of PTSD. Therefore, health professionals might screen the parents of children with chronic illnesses to ascertain whether they could benefit from stress management. By the same token, clinicians should recognize that most parents tend to cope well through reinforcing their adaptive coping skills.
\end{abstract}

Keywords Posttraumatic Stress Disorder, Childhood Cancer, Mothers

\section{Introduction}

Children are their parents' pleasure and treasure. Every family has their hopes, dreams, and expectations regarding normal growth and development for their children. When the life and health of children are threatened; hereafter, when a child is diagnosed with cancer condition, parents mourn the loss of their child's health their expectations and dreams can be challenged and affecting the entire family life. The parents of cancer diagnosed child are mostly under a major stress because the appearance of cancer can cause an emotional crisis (anxiety and/or depression) linked with the fear of death and loss of the previous reality especially the mother who usually take care of the child. Parents of children with cancer are also at risk of developing PTSD. [1]

It was estimated that the childhood cancers prevalent is about $7 \%$ of cancer cases as reported by Ministry of health in Saudi Arabia and the causes are still unknown. Cancer is a generic term for a large group of diseases that can affect any part of the body [2]. Indeed, learning that one's child has a life-threatening disease, as well as witnessing one's child undergoing repeated aversive medical procedures such as lumbar puncture or venipuncture, enduring chemotherapy side effects, and undergoing sometimes painful and disfiguring surgery, can be traumatic for parents. An extensive body of research results indicated that between $10 \%$ and $40 \%$ of parents of pediatric cancer survivors report significant levels of traumatic stress symptoms [3]. A little research in Arabic countries has studied the prevalence of PTSD among mothers of pediatric cancer survivors. Therefore, there is an urgent need to study the emotional experiences among mothers of children cancer survivors to help and support them in caring for the child throughout the cancer journey treatment.

Even though, the survival rates for childhood cancer have 
increased substantially since the 1970 s, approximately 2,200 children die from cancer each year, making the threat of death very real for children and their families [4]. In fact, the diagnosis and treatment of childhood cancer present numerous challenges and sources of stress for children and their parents [4]. One defining feature of cancer is the rapid creation of abnormal cells that grow beyond their usual boundaries, and which can then invade adjoining parts of the body and spread to other organs. This process is referred to as metastasis. Metastases are the major cause of death from cancer. [5]

The child is always seen within the context of the family, who must negotiate multiple potentially traumatic events. For example, parents are usually informed that the diagnosis as a life-threatening condition before pediatric patients and parents make numerous and difficult treatment decisions. Although multiple family members experience the same events, the reaction of the individual family members to these events may be variable [6]. Indeed, illness events are called potentially traumatic events (PTE) because the same objective event may not be equally traumatic to all individuals. [7]. Rather, it is the interaction between the objective nature of the event and the subjective interpretation of an event that determines whether a particular event is perceived as traumatic [8].

Previous research has often found that parents became socially isolated when they have a child with an enduring illness, and this adds significantly to their stress and anxiety [9 - 11]. The mothers reported higher prevalent of a psychological reaction than the fathers according to Bruce [12]. There are numbers of factors such as female gender, greater physical late, prior stressful life events, the severity of cancer and treatment, family conflict, and poor social support. Trauma is common in women; five out of ten women experience a traumatic event. Women tend to experience different traumas than men. As it was reported by Kazak, et.al [13] in their study as they found that $30 \%$ of mothers compared with $20 \%$ of fathers demonstrate cancer-related lifetime PTSD. While both men and women report the same symptoms of PTSD (hyper arousal, re-experiencing, avoidance, and numbing), some symptoms are more common for women or men [14]

Posttraumatic Stress Disorder (PTSD) is a psychiatric disorder that can occur in people who have experienced or witnessed a traumatic event [15]. It can be defined as an anxiety disorder that results from: witnessing or having experienced a life-threatening event or situation, such as, death or having caused the death of another person, or violent personal assault. The result is feelings of intense fear, helplessness or horror. Other responses include guilt, shame, intense anger or feeling emotionally numb. PTSD most commonly occurs in the weeks or months following the trauma. There is some evidence that it may occur years or even decades after the trauma. One of these people who are more likely to get PTSD is parents of children newly diagnosed with cancer, they are exposed to potential trauma such as knowing about the disease, seeing their child in pain, and seeing their children receiving chemotherapy treatment and suffering from its side effects. About 3\% of adult experienced with PTSD after their child was diagnosed with a life-threatening disease such as cancer [16]. In addition, it has been reported that $68 \%$ of mothers and $57 \%$ of fathers of children on cancer treatment report cancer-related PTSS within a moderate to a severe range [17], and $44 \%$ of parents of children on treatment report cancer-related PTSD [17].

In fact, for most parents, the experience of watching their child suffer a cancer episode combined with the strains of a hospital stay with frequent need of intensive care treatment, the necessity of regular follow-up assessments at the hospital and fear of long-term sequelae may be stressful and possibly negatively affect their health-related quality of life [18]. In addition, the parent' acute anxiety at the time of diagnosis and the psychosocial risk may be affected over the course of treatment. Even though, family structure and resources might be shifted but, in most cases, they are not likely to change dramatically [19]. Besides, the health care system or the health care provider are not always trained and skilled at discussing emotional problems with the primary caregiver who is almost have been the mother. The impact on the family cannot be ignored because the diagnosis of cancer in a child also causes psychological effects on the whole family especially mother [1].

Additionally, Arab women, in general, have learned to hide their feelings and pretend that they are healthy, especially when they have crises or traumatic event either affecting herself or someone of her family members. According to studies by Goldblatt, et al., [20] as well as Aziza and Cohen [21], the way Arab women think is very common because these women who are also mothers are expected to be strong for their families, this is why they took the burden of caring of any affected family member. Also, the child with cancer is at risk of developing some psychiatric disturbances such as mood disorders, anxiety disorders, depression and PTSD. Moreover, findings from a large national mental health study show that a little more than half of all women will experience at least one traumatic event in their life. Research findings reported that the most common trauma for women is sexual assault or child sexual abuse followed by domestic violence, or to have a loved one suddenly die or diagnosed with cancer disease.

Undoubtedly, the course and outcome of most childhood illnesses especially cancer disease are strongly prejudiced by both family structure and function, [22]. Therefore, the current study will assess the presence of PTSD symptoms among mothers having a child who is newly diagnosed with pediatric cancer.

\subsection{The Significance of the Study}

Based on the family-centered care model (FCCM) which proposed that health care staff and the family are partners, working together to best meet the sick child's needs. 
Family-centered care (FCC) has been described as a partnership approach to health care decision-making. Because of the increasing number of children diagnosed with cancer in the Kingdom of Saudi Arabia, and the significant increasing responsibilities of the mothers' who are the primary caregiver for children diagnosed with pediatric cancer, as they starting a vicious cycle of anxiety and socioeconomic uncertainty leading her to depression and high prevalent of psychological problems than the fathers, [1]. Moreover, an extensive body of research reported that mothers of children with cancer represent a group prone to high levels of emotional distress and that the period following their child's diagnosis and the initiation of treatment may be predominantly stressful and disturbing leading them to depression. Such mothers have difficulty in taking care of themselves, their household and especially their sick children. There are a number of factors such as female gender, prior stressful life events, a severity of cancer and treatment, family conflict, poor social support. Besides, the healthcare providers are not always trained and skilled in discussing emotional problems with primary health care provider who is almost the mother. In Saudi Arabia, there is still very limited literature on the incidence and prevalence of PTSD among mothers having newly diagnosed with cancer, since most research on PTSD in cancer has been carried out with breast cancer patients. As well there is limited research on the association between post-traumatic stress disorder and the mothers having children newly diagnosed with cancer. Therefore, the current study is looking at the assessment of the PTSD symptoms among Saudi mothers having a child newly diagnosed with cancer.

\subsection{Aim of the Study}

To assess the posttraumatic stress disorder symptoms among mothers who have a child newly diagnosed with cancer.

The study will specifically answer the following research questions:

1. How many mothers will meet the criteria of the PTSD diagnosis?

2. What are the symptoms of PTSD exhibited by Saudi mothers?

3. What is the severity level of PTSD among Saudi mothers?

4. What is the relationship between demographic characteristics and the severity of PTSD?

\section{Participants and Methods}

\subsection{Study Design}

To achieve the objectives of the current study, a descriptive exploratory correlational design was used. As this design will increase the flexibility in the investigation of a relationship between diagnosis of children with cancer and presence of PTSD in their mothers, also this design is an efficient and effective method of collecting a large amount of data about a problem and a potential for evidence-based application in a clinical setting. This design is a very useful design for clinical researcher's ability to manipulate, control, and randomize [23].

Study Area/Setting: The study was conducted in pediatric oncology department (ward11) in-patient, at King Khalid National Guard Hospital (KKNGH) affiliated to Ministry of National Guard health, Jeddah, KSA. The ward bed capacity of this inpatient ward is 26 . The unit is providing care services for the patient from neonatal stage till 14 years of age. The average number of patients' admission of Saudi children is $26-30$ children/month. They admit patients with solid tumors non-solid tumors, and brain tumors too. The oncology department is in a process of opening the Pediatric Bone Marrow Transplantation unit which will have a bed capacity of 6 admissions. There is also a 'Walk In area' for emergency situations as the cancer children do not report to the ER, and they come directly from the unit.

Participants of the study: A non-probability convenience sample of 110 mothers attending with their children to the inpatient pediatric oncology department (ward11) at King Khalid National Guard Hospital (KKNGH) affiliated to Ministry of National Guard health, Jeddah, KSA. The participants have been recruited based on the following criteria:

1. Educated

2. Mothers at any age.

3. Have a child who is newly diagnosed with cancer, or start receiving chemotherapy or start to have the side effect during the first few weeks of treatment in (ward11) at King Khalid National Guard Hospital, Jeddah.

Sample Size: The size of the sample was calculated to be at least 100 mothers. Data collection process was completed within 3 months to reach the required sample size.

\subsection{The Tool of the Study}

The questionnaire comprised two sections:

1. Demographics background of the participants such as: mother age, address, marital status, educational background, father and mother occupation, socioeconomic status, number of children in the family, age of the children, the birth order of the affected child and previous hospitalization and if the mother has history of any medical disorders such as diabetes, hypertension, heart disease, etc.

2. The Posttraumatic Stress Scale - Interview Version for DSM-5 (PSSI-5) [24], The PSSI-5 is developed by Foa and Capaldi [23]. It consists of 20 -item interview measure that requires the 
interviewer to rate each of the DSM-5 symptom criteria on a $0-4$ scale of frequency and/or severity. The PSSI-5 yields both a PTSD diagnosis according to DSM-5 criteria and a measure of PTSD severity. The instrument can indicate the possible diagnosis of PTSD based on whether the rates a score of 1 or higher of the minimum number of symptoms in each cluster as determined by DSM-5 (i.e. 1 re-experiencing, 1 avoidance, 2 cognition and mood, and two arousal/reactivity symptoms) AND at least a 2 or higher on either of the distress or interference items. The PTSD severity will be determined by totaling the 20 PDS-5 symptom ratings (items 1-20). Scores range from 0-80. The following are clinical guidelines for PTSD symptom severity: $0-8$ indicates (Minimal symptoms), $9-18^{\circ}$ (Mild symptoms), 19 - 30 (Moderate symptoms), 31 - 45 (Severe symptoms), and 46 - 80 denotes (Very severe symptoms)

In addition, a score of 23 can be used as a cutoff point for the possible diagnosis of PTSD, with scores between $0-22$ indicating no diagnosis, and $23-80$ indicating the probable diagnosis. The PSSI-5 has been found to have an excellent internal consistency (Cronbach's $\alpha=.89$ ) and very good test-retest reliability ( 1 week: $\mathrm{r}=.87$ ). The PSS-I-5 has comparable psychometric properties to its previous version (PSS-I) based on the DSM-IV and is brief in its administration (30 min) only needed to complete the scale.

The scale was used after little modification in the statements. As the affirmative statement in Arabic translation was used instead of the questions one.

\subsection{Validity and Reliability of the Tool}

For the content validity, the instrument was translated into Arabic language and then back translated into the English language. Back translation aimed at verifying whether the translation covers all aspects of the original English version of the questionnaire or not. Then to ensure the face validity and reliability of the final translated Arabic version of the questionnaire, it was evaluated by a panel of experts who were selected based on their qualifications and experience in nursing research and education. Then, the tool was piloted and tested by 10 mothers with the same inclusion criteria to identify a presence of any ambiguities in questions, the time required for completing the questionnaire. Those mothers were excluded from the main sample of the current study. The reliability coefficient was 0.87 (high reliability) provided with the results of this study.

\subsection{Procedure}

The researchers met the target participants in the pediatric oncology Ward (11) at King Khalid National Guard Hospital (KKNGH) affiliated to Ministry of National Guard health,
Jeddah, KSA. Those were willing to participate as they have been grouped into small groups (8-10) each. The researchers agreed upon to follow up the same steps that required for data collection from 3 groups with continuous allocation until we reached the required (100) sample size. Every researcher followed the following steps:

1. Explanation of the purpose and nature of the study for the participants.

2. Distributing the consent form for the participation in the research,

3. Distributing the questionnaire to the participants.

4. Collecting the completed filled questionnaires from the participants.

\subsection{Data Management and Analysis Plan}

The data was analyzed by using SPSS version 22 . The collected data was coded; validated, and controlled before analysis. Appropriate statistical tests such as descriptive statistics of the prevalence of manifestation of PTSD among mothers, the level of severities and the relationship between the severities of post-traumatic stressed with sociodemographic characteristics use the Spearman Rank Order Correlations. All tests were used in the two-tailed version and $\mathrm{P} 0 \leq 0.05$ was considered as statistically significant.

\subsection{Ethical Considerations}

An official approval from the students' Research Unit, King Abdallah International Medical Research Center (KAIMRC) and Institutional Research Board (IRB No. (SP16/270/J) was received. In addition; an official permission was received from the manager of pediatric oncology department for data collection. The participants were informed about the nature and the purpose of the study, and that their participation is voluntary and they can withdraw from the study at any time. A written consent was obtained from all participants. Confidentiality and anonymity of the collected data was assured

\section{Results}

Table 1 shows the demographic characteristics of 110 mothers who have recruited to achieve the objectives of the current study. The majority (87.3\%) of them were married, (60.9\%) unemployed, (73.6\%) living in Jeddah, and (51.8\%) having a lower level of education. As regard to the number of children, the majority of them (79.1\%) have $1-4$ children and the majority $(87.3 \%)$ have a higher economic level. Most of the participants $(70 \%)$ didn't suffer from any medical disease compared with only $30 \%$ suffered from diabetes, hypertension and cardiac problems. More than half of the sample $(51.8 \%)$ received their child diagnosis $2-5$ monthes ago and a majority $(83.6 \%)$ is the first time to expose to this traumatic situation. Concerning the symptoms onset after 
child diagnosis and its duration, more than 2 third (65.5\%) of the participants began to suffer from PTSD symptoms less than 6 months after the occurrence of the trauma that mean they have acute onset of PTSD compared to $34.5 \%$ of them their symptoms started after more than 6 months that means they have delayed onset of PTSD. As regards to how long the participants had the symptoms related to the traumatic event, $57 \%$ have the manifestations for more than one month while $43 \%$ had the manifestations for less than one month.

Table 1. Demographic Characteristics of the mothers

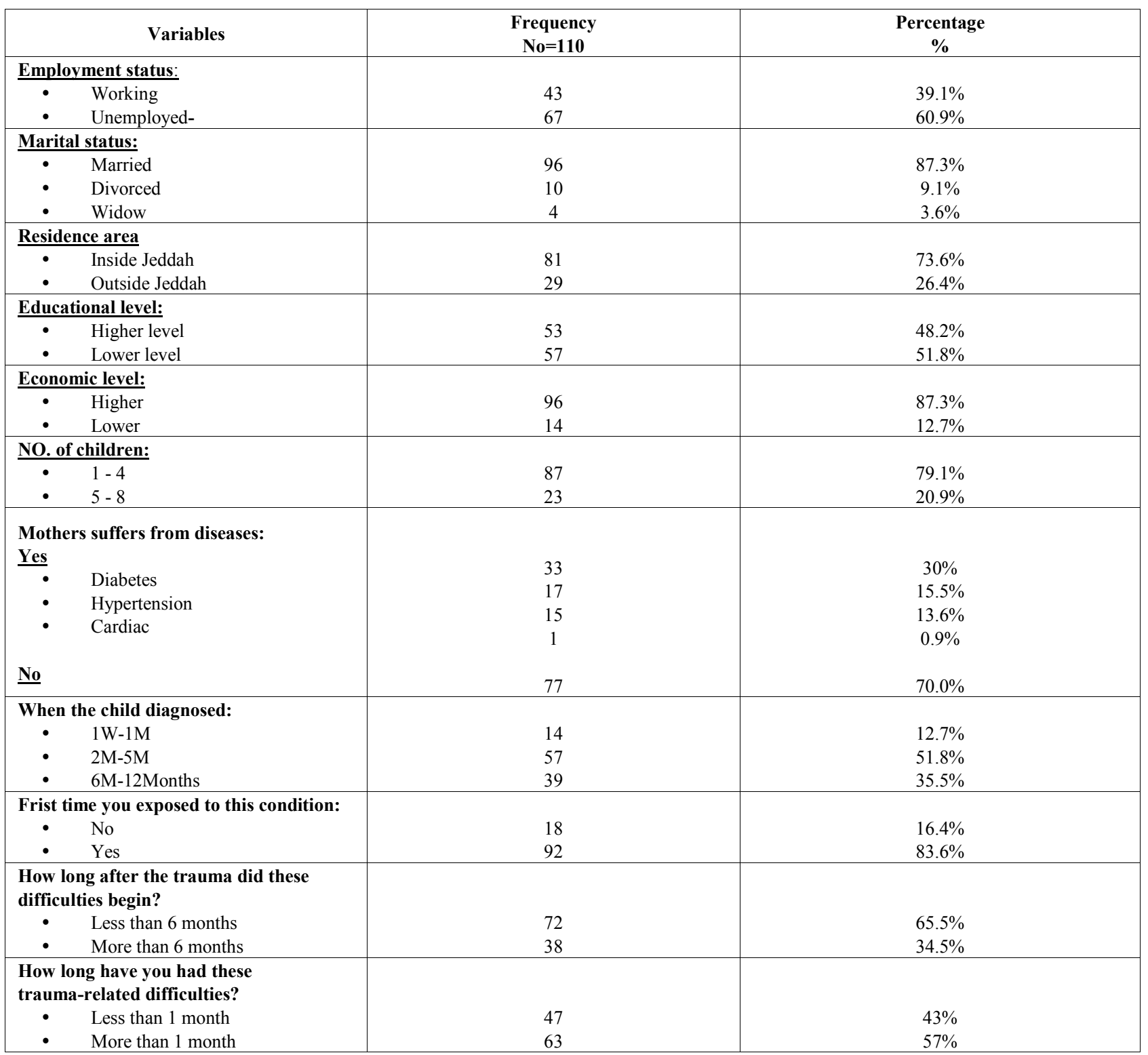

Table 2. Symptoms onset and duration among PTSD diagnosis group and others ones

\begin{tabular}{|c|c|c|c|c|c|c|c|c|}
\hline \multirow{2}{*}{$\begin{array}{c}\text { Variables } \\
\text { Symptoms onset after diagnosis: } \\
\text { Less than } 6 \text { months } \\
\text { More than } 6 \text { months }\end{array}$} & \multicolumn{2}{|c|}{$\begin{array}{c}\text { Total sample } \\
\mathrm{N}=110\end{array}$} & \multicolumn{2}{|c|}{$\begin{array}{c}\text { PTSD n }=36 \\
\text { N \% }\end{array}$} & \multicolumn{2}{|c|}{$\begin{array}{c}\text { Non-PTSD N=74 } \\
\text { N \% }\end{array}$} & \multirow{2}{*}{$\begin{array}{r}\mathbf{X}^{2} \\
2.319\end{array}$} & \multirow{2}{*}{$\begin{array}{r}\mathbf{P} \leq \mathbf{0 . 0 5} \\
.128\end{array}$} \\
\hline & $\begin{array}{l}72 \\
38\end{array}$ & $\begin{array}{l}65.5 \% \\
34.5 \%\end{array}$ & $\begin{array}{l}20 \\
16\end{array}$ & $\begin{array}{l}55.5 \\
44.4\end{array}$ & $\begin{array}{l}52 \\
22\end{array}$ & $\begin{array}{l}70.2 \\
29.7\end{array}$ & & \\
\hline $\begin{array}{c}\text { Symptoms duration after diagnosis: } \\
\text { Less than } 1 \text { month } \\
\text { More than } 1 \text { month }\end{array}$ & $\begin{array}{l}47 \\
63 \\
\end{array}$ & $\begin{array}{l}43 \% \\
57 \%\end{array}$ & $\begin{array}{l}12 \\
24\end{array}$ & $\begin{array}{l}33.3 \\
66.6\end{array}$ & $\begin{array}{l}35 \\
39 \\
\end{array}$ & $\begin{array}{l}47.2 \\
52.7\end{array}$ & 1.930 & .165 \\
\hline
\end{tabular}


$\underline{\text { Table } 2}$ shows that 36 participants were met the criteria for PTSD diagnosis, more than half of them (55.5\%) began to suffer the symptoms less than 6 months since the diagnosis of their children compared with $44.4 \%$ suffered symptoms after more than 6 months while, the majority $70.2 \%$ of non-diagnosed group $(67.3 \%)$ began to suffer symptoms less than 6 months despite they didn't meet the criteria of PTSD diagnosis with no statistically significant differences between the PTSD group and them $\mathrm{P}=0.128$. On the other hand, majority (66.6\%) of PTSD group suffers symptoms for more than 1 month compared with $52.7 \%$ of the non-PTSD group with no significant difference between both of them as $\mathrm{P}=0.165$.

The graph (1) shows the Mothers' psychological reaction when their children were diagnosed with cancer. The majority $(61.8 \%)$ experienced with shock reaction followed by (27.3\%) experienced depression while only (10.9\%) felt panic and anxiety in response to their children diagnosis.

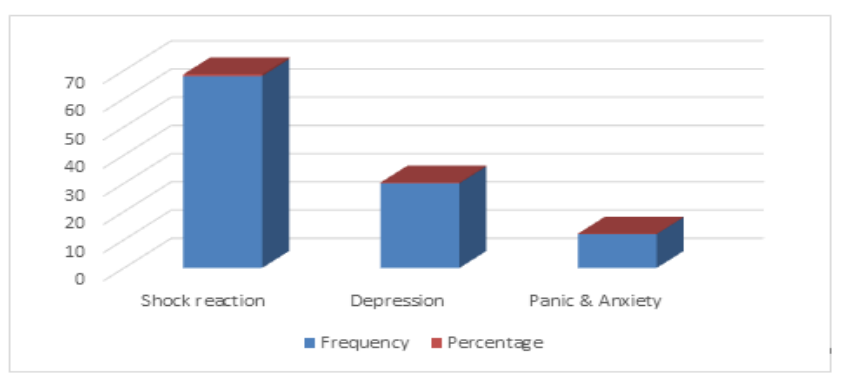

Graph 1. Mother Psychological reaction at the time of child diagnosis of cancer

$\underline{\text { Table } 3}$ shows the demographic characteristics of children of the target mother group as regard to the child birth order half (50.9) of them are ranked as the $3^{\text {rd }}$ child and above. A majority (84.5\%) didn't have other diseases with cancer compared with $(6.36 \%)$ have respiratory diseases, followed by $(5.45 \%)$ diagnosed with medical disorders and only ) $0.9 \%$ ) had congenital disorders. Finally, (42.7\%) of those children is the first time of hospital admission compared with $(25.4 \%)$ and $(34.5 \%)$ have been admitted twice and 3 times and above respectively.

Table 4 shows that the total mean of mothers' age having the probability to the PTSD was $37.6 \pm 9.39$ compared with $32.1 \pm 7.67$ of those have not met the diagnostic criteria for PTSD with no statistically significant difference between PTSD and Non-PTSD group $t=0.271$. Additionally, the table shows that there is a highly significant difference between children total mean age of PTSD and Non-PTSD group as the independent $\mathrm{t}$-test $=0.0001$. On the other hand, the total mean of the time when child diagnosed showed no significant difference between two groups as $\mathrm{t}=0.69$.

Table 5: displays the frequencies and percentages of PTSS clusters (re-experience, avoidance, arousal, and distress and interference) and of each specific PTSD symptom. The most frequent symptoms clusters were Re-experience and distress among all (100\%) participants while $98.1 \%$ of mothers have the cluster of avoidance and arousal. As regard to the re-experiencing cluster displayed symptoms, $34.45 \%$ of the participants were experienced with psychological distress followed by $(25.45 \%)$ and $(21.81 \%)$ experienced with flashback and nightmares respectively. As regard to the avoidance cluster symptoms, the most frequent symptoms were diminished of interest $(20.90 \%)$ followed by a feeling of detachment (17.27\%), and (15.45\%) emotional numbing. While, only (11.81\%) behavioral avoidance and (10.9\%) suffered from psychogenic amnesia. Additionally, the table shows the presence of a highly significant difference between PTSD group and the non-PTSD as $\mathrm{P} \leq 0.5$.

Table 3. Demographic characteristics of the children

\begin{tabular}{|c|c|c|}
\hline Variables & $\begin{array}{c}\text { Frequency } \\
N o=110\end{array}$ & $\begin{array}{c}\text { Percentage } \\
\%\end{array}$ \\
\hline $\begin{array}{cl}\text { Childbirth order: } \\
\text { - } & \text { First child } \\
\text { - } & 2^{\text {nd }} \text { child } \\
\text { • } & \text { 3rd child and above }\end{array}$ & $\begin{array}{l}26 \\
28 \\
56\end{array}$ & $\begin{array}{l}23.6 \% \\
25.5 \% \\
50.9 \%\end{array}$ \\
\hline $\begin{array}{cc}\text { The number of hospitalization: } \\
\text { - } & \text { First time } \\
\text { - } & \text { Second time } \\
\text { - } & \text { Third time and above } \\
\end{array}$ & $\begin{array}{l}47 \\
28 \\
38 \\
\end{array}$ & $\begin{array}{l}42.7 \% \\
25.4 \% \\
34.5 \% \\
\end{array}$ \\
\hline $\begin{array}{ll}\text { Other medical diseases rather than canc } \\
\text { Yes } \\
\cdot & \text { Respiratory disease } \\
\cdot & \text { Medical disorders } \\
\text { - } & \text { Congenital disorders } \\
\text { No } & \end{array}$ & $\begin{array}{c}17 \\
6 \\
7 \\
4 \\
93\end{array}$ & $\begin{array}{c}15.5 \% \\
5.45 \% \\
6.36 \% \\
0.9 \% \\
84.5 \%\end{array}$ \\
\hline
\end{tabular}


Table 4. Independent Sample $\mathrm{T}$ Test of Total $\mathrm{M} \pm \mathrm{SD}$ Of Mothers' and Children Age, And Time of Children Diagnosis.

\begin{tabular}{|c|c|c|c|}
\hline Variables & NO. $=110$ & Mean \pm SD & $t^{*}$ \\
\hline $\begin{array}{ll}\text { Mother age } \\
\bullet & \text { No diagnosis } \\
\cdot & \text { probable diagnosis }\end{array}$ & $\begin{array}{l}74 \\
36\end{array}$ & $\begin{array}{l}32.1 \pm 7.67 \\
37.6 \pm 9.39\end{array}$ & 0.271 \\
\hline 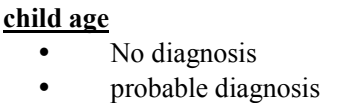 & $\begin{array}{l}74 \\
36\end{array}$ & $\begin{array}{c}41.7 \pm 34.75 \\
76.25 \pm 51.53\end{array}$ & 0.0001 \\
\hline $\begin{array}{cl}\text { Time of child diagnosed } \\
\bullet & \text { No diagnosis } \\
\bullet & \text { Probable diagnosis }\end{array}$ & $\begin{array}{l}74 \\
36\end{array}$ & $\begin{array}{l}4.63 \pm 3.78 \\
6.44 \pm 3.72 \\
\end{array}$ & 0.69 \\
\hline
\end{tabular}

$\mathrm{t}^{*}$ independent sample t-test

Table 5. Association of the severity of PTSD symptoms and the items of the scale $n=110$

\begin{tabular}{|c|c|c|c|c|c|c|c|c|c|}
\hline NO & Statements & $\begin{array}{c}\text { Total } \\
\text { Sample } \\
(n=110)\end{array}$ & $\begin{array}{c}\text { Total } \\
\text { Sample } \\
(100 \%)\end{array}$ & $\begin{array}{c}\text { PTSD } \\
\text { Symptoms } \\
\text { group }(n=36)\end{array}$ & $\begin{array}{c}\text { PTSD } \\
\text { Symptoms } \\
\text { group (\%) }\end{array}$ & $\begin{array}{c}\text { No PTSD } \\
\text { Symptoms } \\
\text { group }(n=74)\end{array}$ & $\begin{array}{l}\text { No PTSD } \\
\text { Symptoms } \\
\text { group (\%) }\end{array}$ & $X^{2}$ & $\begin{array}{c}P \\
\text { value }\end{array}$ \\
\hline I. & $\begin{array}{l}\text { Re-experiencing } \\
\text { symptoms }\end{array}$ & 110 & $100 \%$ & $8=2$ - & $32.72 \%$ & 8 & $67.27 \%$ & 18.944 & .001 \\
\hline 1 & $\begin{array}{c}\text { Intrusive } \\
\text { recollections }\end{array}$ & 9 & $8.18 \%$ & 2 & $22.22 \%$ & 7 & $77.78 \%$ & $19.839^{\mathrm{a}}$ & .000 \\
\hline 2 & Nightmares & 24 & $21.81 \%$ & 6 & $25 \%$ & 18 & $75 \%$ & $30.091^{\mathrm{a}}$ & .000 \\
\hline 3 & Flashbacks & 28 & $25.45 \%$ & 8 & $28.5 \%$ & 20 & $71.5 \%$ & $2.790^{\mathrm{a}}$ & .104 \\
\hline 4 & $\begin{array}{l}\text { Psychological } \\
\text { distress }\end{array}$ & 38 & $34.54 \%$ & 10 & $26.31 \%$ & 28 & $73.68 \%$ & $.149^{\mathrm{a}}$ & .835 \\
\hline 5 & $\begin{array}{l}\text { Physiological } \\
\text { reactivity }\end{array}$ & 11 & $10 \%$ & 10 & $90.90 \%$ & 1 & $9 \%$ & $7.047^{\mathrm{a}}$ & .011 \\
\hline II. & Avoidance & 108 & $98.18 \%$ & 36 & $33.33 \%$ & 72 & $66.67 \%$ & 52.058 & .000 \\
\hline 6 & $\begin{array}{l}\text { Cognitive } \\
\text { Avoidance }\end{array}$ & 3 & $2.72 \%$ & 0 & $0 \%$ & 3 & $100 \%$ & $6.872^{\mathrm{a}}$ & .013 \\
\hline 7 & $\begin{array}{l}\text { Behavioral } \\
\text { avoidance }\end{array}$ & 6 & $5.45 \%$ & 0 & $0 \%$ & 6 & $100 \%$ & $13.858^{\mathrm{a}}$ & .000 \\
\hline 8 & $\begin{array}{c}\text { Psychogenic } \\
\text { amnesia }\end{array}$ & 12 & $10.9 \%$ & 0 & $0 \%$ & 12 & $100 \%$ & $12.542^{\mathrm{a}}$ & .000 \\
\hline 9 & $\begin{array}{c}\text { Diminished of } \\
\text { interest }\end{array}$ & 23 & $20.90 \%$ & 2 & $8.69 \%$ & 21 & $91.30 \%$ & $6.744^{\mathrm{a}}$ & .014 \\
\hline 10 & $\begin{array}{c}\text { Feeling of } \\
\text { detachment }\end{array}$ & 19 & $17.27 \%$ & 4 & $21.05 \%$ & 15 & $78.94 \%$ & $14.374^{\mathrm{a}}$ & .000 \\
\hline 11 & Emotional numbing & 17 & $15.45 \%$ & 7 & $41.17 \%$ & 10 & $58.82 \%$ & $17.647^{\mathrm{a}}$ & .000 \\
\hline 12 & $\begin{array}{c}\text { Sense of } \\
\text { foreshortened } \\
\text { future }\end{array}$ & 8 & $7.27 \%$ & 5 & $62.5 \%$ & 3 & $37.5 \%$ & $13.914^{\mathrm{a}}$ & .000 \\
\hline 13 & $\begin{array}{l}\text { Cognitive } \\
\text { Avoidance } \\
\end{array}$ & 7 & $6.36 \%$ & 6 & $85.71 \%$ & 1 & $14.28 \%$ & $9.822^{\mathrm{a}}$ & .002 \\
\hline 14 & $\begin{array}{c}\text { Behavioral } \\
\text { avoidance }\end{array}$ & 13 & $11.81 \%$ & 12 & $92.30 \%$ & 1 & $7.69 \%$ & $13.858^{\mathrm{a}}$ & .000 \\
\hline III. & $\begin{array}{c}\text { Increased arousal } \\
\text { and reactivity }\end{array}$ & 108 & $98.18 \%$ & 36 & $33.33 \%$ & 72 & $66.67 \%$ & $31.639^{\mathrm{a}}$ & .000 \\
\hline 15 & Insomnia & 18 & $16.36 \%$ & 2 & $11.11 \%$ & 16 & $88.89 \%$ & $8.675^{\mathrm{a}}$ & .004 \\
\hline 16 & Irritability & 21 & $19.09 \%$ & 3 & $14.28 \%$ & 18 & $85.71 \%$ & $11.464^{\mathrm{a}}$ & .001 \\
\hline 17 & $\begin{array}{c}\text { Difficulty } \\
\text { concentrating }\end{array}$ & 20 & $18.18 \%$ & 3 & $15 \%$ & 17 & $85 \%$ & $12.837^{\mathrm{a}}$ & .001 \\
\hline 18 & Hypervigilance & 23 & $20.90 \%$ & 9 & $39.13 \%$ & 14 & $60.86 \%$ & $7.730^{\mathrm{a}}$ & .007 \\
\hline 19 & $\begin{array}{l}\text { Exaggerated startle } \\
\text { response }\end{array}$ & 18 & $16.36 \%$ & 12 & $66.66 \%$ & 6 & $33.33 \%$ & $5.185^{\mathrm{a}}$ & .035 \\
\hline IV. & $\begin{array}{l}\text { Distress and } \\
\text { Interference }\end{array}$ & 110 & $100 \%$ & 36 & $32.72 \%$ & 74 & $67.27 \%$ & $11.357^{\mathrm{a}}$ & .001 \\
\hline 21 & $\begin{array}{l}\text { Distress and } \\
\text { overwhelming }\end{array}$ & 36 & $32.72 \%$ & 4 & $11.11 \%$ & 32 & $88.88 \%$ & $11.357^{\mathrm{a}}$ & .001 \\
\hline 22 & $\begin{array}{l}\text { Interference with } \\
\text { daily activities }\end{array}$ & 74 & $67.27 \%$ & 32 & $43.24 \%$ & 42 & $56.75 \%$ & $11.357^{\mathrm{a}}$ & .001 \\
\hline
\end{tabular}

PTSD: posttraumatic stress disorder.

$\dagger$ Fisher's exact test. 
Concerning the cluster of arousal, the most frequently $(20.90 \%)$ reported symptom was hypervigilance in the whole sample $(98.18 \%)$ followed by irritability $(19.09 \%)$ and difficulty of concentration (18.18\%) with an equal number of participants $(16.36 \%)$ reported insomnia and exaggerated startle response with highly significant difference between PTSD group and the other group as $\mathbf{P} \leq 0.5$ and $\mathbf{X}^{2}=7.730^{\mathrm{a}}$, $11.464^{\mathrm{a}}, 12.837^{\mathrm{a}}$, and $8.675^{\mathrm{a}}$ respectively. Regarding the cluster of distress and interference with daily activities, the most frequent $(67.27 \%)$ reported symptoms was interference with daily activity compared with only $(32.72 \%)$ reported symptoms distress and overwhelming with higher significant difference between PTSD group and the other group as $\mathrm{X}^{2}=$ 11.464a and $\mathrm{P}=.00$

Bar graph (2) shows the mothers' distribution of the severity of PTSD disorders. $61.8 \%$ have mild symptoms followed by $23.7 \%$ having severe symptoms compared with $14.5 \%$ suffering from moderate symptoms. $9.1 \%$ out of them $(14.5 \%)$ were met the diagnostic criteria for PTSD when using cutoff point of the scale (23 -30) compared to 5.5\% were (19-22) didn't meet the criteria of diagnosis. Therefore $32.7 \%$ of the participants meet the criteria of PTSD diagnosis compared with $67.3 \%$ who didn't meet the criteria for PTSD.

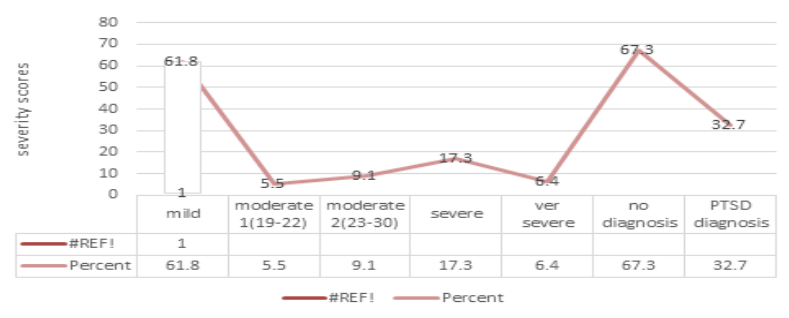

Bar graph 2. Mothers' distribution according to severity symptoms of PTSD

Table (6) shows the presence of highly significance difference and the association between the presence of PTSD diagnosis and the demographic characteristics of the participants as $(\mathrm{P} \leq 0.001)$ except for residence area and child birth order as $\mathrm{P}=.493$ and .598 respectively.

Table 6. Association of demographic characteristics and diagnosis of mothers with PTSD:

\begin{tabular}{|c|c|c|c|c|}
\hline Demographic characteristics & No diagnosis & PTSD diagnosis & $\chi^{2}$ & p-value $\leq 0.001$ \\
\hline \begin{tabular}{cl}
\multicolumn{2}{l}{ Economic level } \\
$\bullet$ & High \\
$\bullet$ & Moderate
\end{tabular} & $\begin{array}{c}3 \\
71\end{array}$ & $\begin{array}{l}11 \\
25\end{array}$ & $15.313^{\mathrm{a}}$ & .000 \\
\hline 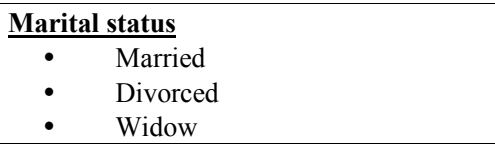 & $\begin{array}{l}70 \\
4 \\
0\end{array}$ & $\begin{array}{c}26 \\
6 \\
4\end{array}$ & $12.990^{\mathrm{a}}$ & .002 \\
\hline $\begin{array}{cl}\text { Mother } & \text { Medical Problem } \\
\bullet & \text { None } \\
\bullet & \text { Diabetes } \\
\bullet & \text { Hypertension } \\
\text { - } & \text { Cardiac disease }\end{array}$ & $\begin{array}{c}51 \\
10 \\
7 \\
0 \\
0\end{array}$ & $\begin{array}{c}26 \\
7 \\
8 \\
0 \\
1\end{array}$ & $29.200^{\mathrm{a}}$ & .004 \\
\hline \begin{tabular}{cc}
\multicolumn{2}{l}{ Previous exposure to same condition } \\
$\bullet$ & Yes \\
$\bullet$ & No \\
\end{tabular} & $\begin{array}{c}4 \\
45\end{array}$ & $\begin{array}{l}14 \\
12 \\
\end{array}$ & $19.839^{\mathrm{a}}$ & .000 \\
\hline \begin{tabular}{cc}
\multicolumn{2}{l}{ Educational level } \\
$\bullet$ & Lower level \\
$\bullet$ & High level \\
\end{tabular} & $\begin{array}{l}29 \\
55\end{array}$ & $\begin{array}{l}24 \\
26\end{array}$ & $7.324^{\mathrm{a}}$ & .006 \\
\hline \begin{tabular}{cl}
\multicolumn{2}{l}{ Residence area } \\
$\bullet \quad$ Inside Jeddah \\
$\bullet \quad$ Outside Jeddah
\end{tabular} & $\begin{array}{c}19 \\
6\end{array}$ & $\begin{array}{l}10 \\
11\end{array}$ & $.055^{\mathrm{a}}$ & .493 \\
\hline \begin{tabular}{cc}
\multicolumn{2}{l}{ Other child problem } \\
$\bullet \quad$ Yes \\
$\bullet \quad$ No \\
\end{tabular} & $\begin{array}{l}62 \\
17 \\
\end{array}$ & $\begin{array}{c}31 \\
9 \\
\end{array}$ & $12.246^{\mathrm{a}}$ & .016 \\
\hline \begin{tabular}{cl}
\multicolumn{2}{l}{ Childbirth order } \\
$\bullet$ & First \\
$\bullet$ & Second \\
$\bullet$ & Third and above \\
\end{tabular} & $\begin{array}{l}21 \\
36\end{array}$ & $\begin{array}{c}7 \\
20\end{array}$ & $1.028^{\mathrm{a}}$ & .598 \\
\hline \begin{tabular}{cl}
\multicolumn{2}{l}{ Psychological reaction of mothers } \\
- & Shock \\
- & Depression \\
- & Panic and anxiety \\
\end{tabular} & $\begin{array}{c}48 \\
18 \\
8\end{array}$ & $\begin{array}{c}16 \\
12 \\
8\end{array}$ & $4.625^{\mathrm{a}}$ & .009 \\
\hline $\begin{array}{l}\text { No. of children in the family: } \\
\begin{array}{cc}\text { - } & 1-4 \\
\text { - } & 5-8 \\
\end{array}\end{array}$ & $\begin{array}{l}64 \\
10\end{array}$ & $\begin{array}{l}23 \\
13\end{array}$ & $7.478^{\mathrm{a}}$ & .007 \\
\hline $\begin{array}{cl}\text { No. of hospitalization: } \\
\text { - } & \text { First } \\
\text { - } & \text { Second } \\
\text { - } & \text { Third and above } \\
\end{array}$ & $\begin{array}{l}42 \\
22 \\
10\end{array}$ & $\begin{array}{c}5 \\
6 \\
25\end{array}$ & $37.124^{\mathrm{a}}$ & .000 \\
\hline
\end{tabular}


Table 7 T-test of mothers' employment state. The table shows a negative significant difference $t=-3.251$ between those who is working and others as $\mathrm{P}=.002$

Table 7. The t-test of mothers' employment state:

\begin{tabular}{|l|c|c|c|}
\hline \multicolumn{1}{|c|}{ Variable } & N & T-test & P $\leq \mathbf{0 . 0 0 1}$ \\
\hline Mother job: & & & \\
\hline - Employee & 43 & -3.251 & .002 \\
\hline
\end{tabular}

\section{Discussion}

\subsection{Post-Trauma Stress Disorders Severity Symptoms and Psychological Reaction among Participants of Study}

To the best of our knowledge, this is the first study that investigates the presence of PTSD symptoms among Saudi mothers having newly diagnosed cancer children. The results of the current study revealed that $(32.7 \%)$ of the mothers met the diagnostic criteria for a diagnosis of PTSD, $23.70 \%$ of whom have severe symptoms of PTSD by $9.1 \%$ suffering from moderate symptoms of post-trauma stress disorders. This result is congruent with Masa'deh and Jarrah. [25] in their study aimed at exploring the severity symptoms of "Post Traumatic Stress Disorder in Jordanian Parents of Children with Cancer" as they found that mothers reported significantly higher PTSD levels than fathers. Nemours studies reported higher levels of stress, anxiety, depression, PTSS and PTSD than fathers [26-30]. Additionally, these findings were in the same line with the results reported by Masa'deh, et al. [31].

Despite fathers were not assessed in the current study for the level of PTSD symptoms, many studies reported that mothers always reported higher PTSD levels than fathers. This may be due to the gender effect in perceiving stressors and coping with traumatic events [32-34]. Additionally, mother as a primary caregiver are always taking care, worrying and perceiving every trauma or crises occurred for any one of her children as a stressful situation, this might give an interpretation of the obtained results that birth order of the child has no significance difference between post trauma group and the other non-diagnosed one. The interpretation of the obtained current results was given by mothers themselves when asking about the child birth order They reported that "child's life is precious and unrepeatable no matter if it's the first child or last one".

In fact, the perception of traumatic events and stress has been investigated in previous studies [35, 33]. The difference of perception of trauma among the participants in the current study could give an explanation of why $(67.3 \%)$ of the participants didn't meet the criteria of PTSD diagnosis despite they were exposed to the same circumstances. There are three main premises which could clarify the differences in perception and the psychological reaction to the traumatic situation among participants. Firstly, the differential exposure hypothesis proposes that some people might have at higher risk for PTSD than others simply because they have greater exposure to stressors $[35,36]$. Secondly ,it proposes that even when people face the same identical traumatic situation, people still differ in their susceptibility, tolerance or resistance; such differences may result from variations in an appraisal of the stressor, reactivity, and the effectiveness of the coping mechanism [37]. Thirdly, the differences in perceiving demands and available resources could also explain the differences in reaction to the trauma among people [38].

Research studies proposed that, people who exposed to type 1 trauma (single incident traumatic event) results in re-experiencing, avoiding, and increased arousal, and that type 2 trauma (chronic or prolonged exposure to trauma) results in denial, numbing, dissociation, and rage $[39,40]$ (Terr, (1991) and Cabizuca, et al. (2010). Accordingly, the majority of PTSD group in the current study were type 1 trauma (single incident traumatic situation) with a high significant difference between PTSD and non-PTSD group. Accordingly, acute traumatic cases tend to display sleep pattern disturbances, physiologic hyper arousal, and re-experiencing manifestations, while chronic individuals show more detachment, circumscribed emotions of sadness, and indifference $[41,40]$.Therefore, hypervigilance exaggerated startled response, detachment, behavioral and cognitive avoidance and physiological reactivity were the most frequently reported symptoms experienced by PTSD group and these symptoms were the most that achieved the highest statistical significance when mothers with and without post-traumatic symptoms were compared. Both symptoms of hypervigilance and physiological reactivity may be related to physical symptoms. In fact, physiological reactivity is in itself a physical symptom and hypervigilance is a symptom of the hyper arousal cluster which has been found to be closely associated with physical health in some trauma samples [42]. These findings are in the same line of the finding of Cabizuca, et al. [40]. Nevertheless, the current study revealed that arousal and avoidance were the most frequent symptoms clusters exhibited by the participants (Table 5). Our findings dovetail with Libov et al. [43] who observed that the avoidance cluster was as frequent as the arousal cluster in mothers of patients with cancer. However, our findings are inconsistent with the finding of Cabizuca, et al. [40] and those others researchers that have assessed the prevalence of PTSD clusters in parents of children with serious medical illnesses Kazak et al. [13], Landolt et al., [44], Landolt et al., [45], and Manne et al., [46] and reported that the avoidance cluster was the less frequently found condition.

As regard to the psychological reaction of mothers at the time of child diagnosis, the majority $(61.8 \%)$ experienced with shock reaction followed by $(27.3 \%)$ experienced depression while only $(10.9 \%)$ felt panic and anxiety in response to their children diagnosis. This result is in the same 
line of (Dixon-Woods et al.,) [47] and (McGrath, and Chesler,) [48] who reported that parents may experience shock, numbness, and disbelief at the time of children diagnosis with cancer. Parents may experience a range of emotions at the time of diagnosis and during the early treatment phase, for example, fear shock, and worry about the threat to their child's life [49]. They may also experience guilt and self-reproach about not having been effective advocates for their child during the diagnostic process to face up to the demanding situation Parents may "put life on hold" and ignore their own needs and feelings. This can have an impact on work and social life. Problems with relationships and feelings of grief may arise [50]. The time since diagnosis was found to affect both mothers and fathers of a child with cancer. [49 \& 24]

The current study findings reported that more than half of PTSD group (55.5\%) began to suffer the symptoms less than 6 months since the diagnosis of their children and $(66.6 \%)$ of PTSD group suffers symptoms for more than 1 month (table 2). In fact, many previous studies investigated perceived stress in parents of children with cancer over time and found that parents have the highest stress levels at the time of diagnosis of their children with cancer. [22], [51-52]. Patino-Fernandez et al. [53] investigated stress in parents (i.e. 128 mothers and 72 fathers) of children newly diagnosed with different types of cancer in the US. They found that acute stress symptoms were significant in about $50 \%$ of participants two weeks after the diagnosis. The child's diagnosis is often the first potentially traumatic event as seeing the child in pain, experiencing procedural distress, and being in emergency situations. Therefore, parents' everyday lives during the child's illness are often changing and become very demanding especially, when the majority of the participants are the first time exposed to these traumatic events (Table 1). Mothers will have, for example, frequent clinical appointments, multiple hospitalizations, and administration of medication, together with the perceived need of checking the child's health status and upholding the child's intake of food and fluids, despite possible lack of appetite and a sore mouth. The demanding situation may result in increased vulnerability to traumatic events and thereby increase the risk of posttraumatic stress symptoms (PTSS) and PTSD.

Moreover, the findings from this study showed that the older the child and the mothers the more severe the symptoms experienced by the mothers table (4) since the time of child diagnosis showed non-significant difference between PTSD $(6.44 \pm 3.72)$ and non-PTSD $(4.63 \pm 3.78)$ group, it means that the time since children diagnosis had no correlation with PTSD levels for mothers. This result is contradicting the findings of Masa'deh and Jarrah, (2016) who found a negative significant correlation between time of children diagnosis and experienced level of PTSD among participants which means that the shorter the time since the child diagnosed with cancer the higher the PTSD levels experienced by mothers. Moreover, Pai et al. [19] reviewed
29 articles published between 1967 and 2005 which examined the effect of pediatric cancer on parents. Their review concluded that the first year after diagnosis was the most stressful period for the parents, but such stresses often decrease over time. Therefore, it has been suggested that a psychiatric consultation is very necessary for all parents of children with cancer at the time of diagnosis.

According to a so-called traumatic care model, developed by Kazak et al., [54], all family members' emotional distress and care needs should be attended to when a child is acutely or chronically ill, e.g. diagnosed with cancer. Psychosocial care corresponding to the family members' psychosocial function and needs should be provided. It is observed that parents used a diversity of coping strategies to adapt to their traumatic situation, for example using available support from the social network and health care providers [55], using religion rituals and prayers especially they are Muslims. In fact, the setting which the children will be treated in is considered an important factor in decreasing level of stress among parents. The clinical setting of the current study is King Abdullah Medical City Affiliated to National Guard Health Affairs hence when parents recognize that their children accepted to be treated there, they realized that their children are getting the best available treatment and care, emotional support, the proper information, and the active participation in care and decision-making of their children. Furthermore, parents may felt rest assured as the physical environment at the ward is well designed and their children are being cared for by highly qualified staff who are able to recognize and meet parents' and child's needs of rest and recreation [56] \& [57] James et al., (2004). All of these factors have been reported as important aspects of care for parents of children with cancer [56\&58]. Therefore, it is concluded that such coping mechanism might explain why stress level decreased over time among participants having traumatic situation [59]

\subsection{PTSD Levels, Demographic Characteristics, and Participants Employment Status}

PTSD levels were found to differ according to the employment status employed vs. unemployed, which is generally higher among the house working mothers. The results of the current study indicated that mothers' employment state has a negative significant difference $\mathrm{t}=$ -3.251 between those who is working and others as $\mathrm{P}=.002$. A short time ago, according to Saudi culture, rules and regulations women prohibited from getting outside the home either for education or working. As the commandment of the land in Saudi Arabia requires that working women should be separated from the men and have their own area and facilities, where they can be fully protected from the men within the company. Companies that employ women are inspected to ensure that these rules are followed and penalties can be imposed if a company is not fully complying with the regulations. Moreover, Al-Khateeb[60] reported that Saudi 
men and women are brought up to believe that housework is a woman's responsibility; men only are the breadwinners of the family. When women enter the labor force, they add a new role to their traditional role. Both roles demand a great deal of women's time, energy, and skill. Saudi fathers are only responsible for payment while working mothers are frequently accused in the media of being neglectful of their children and families, on the one hand, and uncommitted and unproductive in their work on the other. Many previous studies showed that the financial status of parents, associated with unemployment, is traumatic and is considered to be a predictor of high-stress levels generally as well as PTSD [61] but this also provides an explanation for the obtained findings from this study as majority were moderate economic state with higher significant difference between PTSD and the non-PTSD group that mean the more the financial constraints the families have, the more the children caring load that lead to more physical and psychological stress.

Many research studies reported that there are many factors that increased the risk and vulnerability to PTSD including individual pre-existing factors, and factors related to the traumatic event either the trauma responses or post-trauma factors [62]. The sociodemographic factors have been associated with PTSD [53] are mothers having experienced previous trauma, perceived life threat at the time of the child's diagnosis, the length of child hospitalization, the child's functional or associated health problems and relapse have been associated with PTSS among mothers of children on treatment. Additionally, parent and child age, economic status, parent perceptions of procedures and treatment intensity and time since diagnosis. Furthermore, parents' age, gender, and education status, have been associated with PTSD among parents of children on [63, 64] and off $(63,64$ and 65] treatment. Accordingly, and congruently with the literature and research studies, the correlation between the demographic characteristics of the participants of the current study and the level of PTSD symptoms, the findings reported the presence of highly significance difference between the PTSD diagnosis and non-diagnostic one as regard to their demographic characteristics as $(\mathrm{P} \leq 0.001)$ table $(6)$.

As regard to the residence area of the participants, there is no significant difference between participants living inside or outside Jeddah as $\mathrm{P}=.493$. This finding is in the same lime with findings of McCarthy et al., [48] who reported that parent living outside the metropolitan area. They may face life stressors associated with less social support, self-perception and identity issues. In the current study, mothers, living outside the Jeddah, may face other life stressors such as transportation problems as the distances is very long between the Medical City inside Jeddah and mothers who live outside Jeddah which impact their future plans and broader family stressors specially for female as they are prohibited from driving in Saudi Arabia and they have to wait either for her husband or special driver to go to hospital or back to home.

\section{Limitation of the Study}

Some methodological concerns of the present study need to be addressed such as using of descriptive design. There was no control group, convenience sampling technique, and use of self-reported questionnaires from only mothers of children.

\section{Conclusions and Recommendations}

Consistent with previous studies, the results of the current study showed that parenting a child with cancer is traumatic. Cancer diagnosis, treatment options, the seriousness of the side effects and many other factors contribute to the degree of the trauma that makes parents of the child diagnosed with cancer liable to have PTSD. Hypervigilance exaggerated startled response, detachment, behavioral and cognitive avoidance and physiological reactivity were the most frequently reported symptoms experienced by PTSD group. Additionally, the older the age of mothers and the higher the risk of increased level of severity of PTSD the affected children. Moreover, the pre-existing factors such as the number of children, educational state, living in or outside Jeddah and economic state of the family can affect the level of severity of PTSD. Therefore, it is recommended that health professionals might monitor the parents of children with chronic illnesses to ascertain whether they could benefit from stress management. By the same token, clinicians should recognize that most parents tend to cope well through reinforcing their adaptive coping skills. Moreover, these findings provide evidence about the need for the provision of psychological support for families caring for a child diagnosed with cancer. Moreover, these results may be effective for health care providers when designing interventions / parental support program to reduce the risk of PTSD. These interventions should take into consideration that both parents need thorough attention and care, with special consideration for the mothers who are at higher risk of PTSD than fathers.

\section{Clinical Implications}

- Consistently with other research studies (Manne et.al, [66]); (Libov and, Nevid [43]; Kazak et. al., [13] (Pöder, [49] and (Masa'deh and Jarrah, [24]), parents, specifically mothers having newly diagnosed cancer child are at greater vulnerability to develop different level of severity symptoms of PTSD.

- Clinically, our results suggest that early screening of parents is required for their children at risk for developing psychosocial difficulties congruent with findings of Nakajima-Yamaguchi et al., [67] and Rechenberg, Grey, and Sadler, [68] who reported that psychosocial problems in children with cancer are related to parental PTSS, not demographic and 
medical factors, and stress and PTSS in mothers adversely affected children's health and prognosis.

- There is an urgent demand that healthcare providers should be trained on psychosocial vulnerability assessment and evaluation either to be able to evaluate the vulnerability to PTSS of parents of a child with cancer and support them or to make this suitable referral in the suitable time

\section{Acknowledgements}

The authors thank all mothers who agreed to participate in the current study and the nursing staffs working in the oncology department for their support throughout data collection. Our gratitude is also extended to Dr. Houida Helal for her effort in doing the statistical analysis of the current study.

\section{REFERENCES}

[1] Ghufran M, Andrades M, NanjiK (2014). Frequency and severity of depression among mothers of children with cancer: Results from a teaching hospital in Karachi, Pakistan. BJMP; 7(1): a701.

[2] Ministry of Health (2012) Childhood Cancer. Aspx Retrieved from http://www.moh.gov.sa/en/healthawareness/educationalconte nt/diseases/cancer/pages/cancer- Kingdom of Saudi Arabia, http://www.moh.gov.sa/

[3] Currier, J., Jobe-Shields, L., Phipps, S. (2009). Stressful Life Events and Posttraumatic Stress Symptoms in Children with Cancer in J Trauma Stress; 22(1): 28-35. DOI10.1007/s00467-015-3294-0

[4] Kholasehzadeh, S. Shiryazdi, H. Neamatzadeh, and N. Ahmadi (2014). Depression levels among mothers of children with leukemia. Iranian Journal of Pediatric Hematology Oncology, 4(3), 109-13. Retrieved from

https:/www.ncbi.nlm.nih.gov/pmc/articles/pmid/25254089/

[5] World health organization (2015). Childhood Cancer. Retrieved from

http://www.WHO.int/mediacentre/factsheets/fs297/en/

[6] Kazak, A, Boeving, C, Alderfer, M, Hwang, W-T, \& Reilly, A (2005). Posttraumatic stress symptoms during treatment in parents of children with cancer. Journal of Clinical Oncology, $23,7405-7410$.

[7] Tremolada, S. Bonichini, S. Schiavo, and Pillon M. (2012). Post-traumatic stress symptoms in mothers of children with leukemia undergoing the first 12 months of therapy: Predictive models. Psychology \& Health. 27(12), 1448-1462. Retrieved from

http://www.tandfonline.com/doi/pdf/10.1080/08870446.2012. 690414? needAccess $=$ true \& redirect $=1$

[8] Yehuda R., Hoge C., McFarlane A., Vermetten E., Lanius R., Nievergelt C., Hobfoll S., Koenen K., Thomas C., Neylan \& Hyman S., (2015) Post-traumatic stress disorder. Nature Reviews Disease Primers 1, Article number: 15057 doi:10.1038/nrdp. 2015.57
[9] Brown R. T. (2008). Single parents of children with chronic illness: An understudied phenomenon. Journal of Pediatric Psychology. 33(4), 408-421. Retrieved from https://www.ncbi.nlm.nih.gov/pmc/articles/PMC2410208/pdf /nihms43848.pdf

[10] Chiou H., and Hsieh L., (2008). Parenting stress in parents of children with epilepsy and asthma. Journal of Child Neurology. 23(3), 301-306. Retrieved from http://jcn.sagepub.com/content/23/3/301.full.pdf

[11] Kratz L., Uding N., Trahms C. M., Villareale, N. and Kieckhefer G. M. (2009). Managing childhood chronic illness: Parent perspectives and implications for parent-provider relationships. Families, Systems, \& Health. 27(4), 303-313. Retrieved from http://psycnet.apa.org/journals/fsh/27/4/303/

[12] Bruce M. (2006). A systematic and conceptual review of posttraumatic stress in childhood cancer survivors and their parents. Clinical Psychology Review. 26(3), 233-256. Retrieved from

http://www.sciencedirect.com/science/article/pii/S027273580 5001340

[13] Kazak, AE, Alderfer, M, Rourke, MT, Simms, S, Streisand, R, \& Grossman, JR (2004). Posttraumatic stress disorder and posttraumatic stress symptoms in families of adolescent childhood cancer survivors. Journal of Pediatric Psychology, 29, 211-219.

[14] Essen. LV, Klugman. GU, Pôder. UL, (2007). Posttraumatic stress disorder among parents of children on cancer treatment: a longitudinal study.

[15] American Psychiatric Nurses Association (2015) what is posttraumatic stress disorder? https://www.psychiatry.org/patients-families/ptsd/what-is-pts d

[16] Breslau N. and E. L. Peterson (2010). Assaultive violence and the risk of posttraumatic stress disorder following a subsequent trauma. Behaviour Research and Therapy. 48(10), 1063-1066. Retrieved from http://www.ncbi.nlm.nih.gov/pmc/articles/PMC2935269/pdf/ nihms222328.pdf

[17] Lutz Stehl, Kazak, Alderfer, Rodriguez, Hwang, Pai, Boeving, and Reilly, (2009) Conducting a Randomized Clinical Trial of a Psychological Intervention for Parents/Caregivers of Children with Cancer Shortly after Diagnosis. J Pediatr Psychol.; 34(8): 803-816.

[18] Buder K., Werner H., , Landolt M., Neuhaus T., Laube G., \& Spartà1 G., (2015) Health-related quality of life and mental health in parents of children with the hemolytic uremic syndrome. Pediatric Nephrology. 31(6), 923-932.

[19] Pai, ALH, Greenley, RN, Lewandowski, A, Drotar, D, Youngstrom, E, \& Peterson, CC (2007). A meta-analytic review of the influence of pediatric cancer on parent and family functioning. Journal of Family Psychology, 21, 407415.

[20] Goldblatt M., Cohen F., Azaiza, and Manassa R., (2012). Being within or being between? The cultural context of Arab women's experience of coping with breast cancer in Israel. Psycho-Oncology. 22(4), 869-875. Retrieved from http://www.ncbi.nlm.nih.gov/pubmed/22473753 
[21] Azaiza, F. \& Cohen, M. (2008). Between traditional and modern perceptions of breast and cervical cancer screenings: a qualitative study of Arab women in Israel. Psycho-Oncology, $17(1), 34-41$.

[22] Manual for the Administration and Scoring of the PTSD Symptom Scale - Interview for DSM-5(PSS-I-5). Retrieved from

https://div12.org/wp-content/uploads/2014/11/PSSI-5-Manua 1.pdf

[23] Polit D. and Beck C. (2007) Essentials of Nursing Research: Appraising Evidence for Nursing Practice. $7^{\text {th }}$ edition, Lippincott Williams and Watkins Company.

[24] Maurice-Stam, F. Oort, B., Last, and Grootenhuis M., (2008). Emotional functioning of parents of children with cancer: The first five years of continuous remission after the end of treatment. Psycho-Oncology. 17(5), 448-459.Retrieved from http://onlinelibrary.wiley.com/doi/10.1002/pon.1260/epdf?r3 _referer=wol\&tracking_action=preview_click\&show_checko $\overline{\mathrm{ut}}=1$ \&purchase_referrer $=$ onlinelibrary. wiley.com\&purchase site_license=LICENSE_DENIED_NO_CUSTOMER

[25] Foa E., and Capaldi S., (2013) The Posttraumatic Stress Scale - Interview Version for DSM-5 (PSSI-5) (revised 05/13)

[26] Masa'deh R,\& Jarrah S (2017) Post Traumatic Stress Disorder in Parents of Children With Cancer in Jordan, Archives of Psychiatric Nursing, 31; 8 -12.

[27] Burke, K, Muscara, F, Mccarthy, M, Dimovski, A, Hearps, S, Anderson, V, \& Walser, R (2014). Adapting acceptance and commitment therapy for parents of children with life-threatening illness: Pilot study. Families, Systems, \& Health, 32, 122-127.

[28] Kazak AE, Alderfer M, Rourke MT, Simms S, Streisand R, Grossman JR. (2004) Posttraumatic stress disorder (PTSD) and posttraumatic stress symptoms (PTSS) in families of adolescent childhood cancer survivors. J Pediatr Psychol; 29(3):211-9.

[29] Kazak E., (2005). Evidence-based interventions for survivors of childhood cancer and their families. Journal of Pediatric Psychology. 30(1), 29-39. Retrieved from http://jpepsy.oxfordjournals.org/content/30/1/29.

[30] Masa'deh, R, Bawadi, H, Saifan, A, \& Aburuz, M (2015). Perceived stress of Jordanian parents: A comparative study between mothers and fathers. Journal of Nursing Education and Practice, 5, p89.

[31] Myers, RM, Balsamo, L, Lu, X, Devidas, M, Hunger, SP, Carroll, WL. Kadan-Lottick, NS (2014). A prospective study of anxiety, depression, and behavioral changes in the first year after a diagnosis of childhood acute lymphoblastic leukemia. Cancer, 120, 1417-1425.

[32] Masa'deh, R, Collier, J, Hall, C, \& Alhalaiqa, F (2013). Predictors of the stress of parents of a child with cancer: A Jordanian Perspective. Global Journal of Health Science, 5, (6) p 81. doi:10.5539/gjhs. v5n6p81

[33] Clarke, NE, Mccarthy, MC, Downie, P, Ashley, DM, \& Anderson, VA (2009). Gender differences in the psychosocial experience of parents of children with cancer: A review of the literature. Psycho-Oncology, 18, 907-915.
[34] Hungerbuehler, I, Vollrath, ME, \& Landolt, MA (2011). Posttraumatic growth in mothers and fathers of children with severe illnesses. Journal of Health Psychology, 16, 12591267.

[35] Verma, R, Balhara, Y, \& Gupta, C (2011). Gender differences in stress response: the role of developmental and biological determinants. ISBN 978-91-554-7204-7. urn: NBN:se: uu: diva-8745

[36] Tomova, L, Von Dawans, B, Heinrichs, M, Silani, G, \& Lamm, C (2014). Is stress affecting our ability to tune into others? Evidence for gender differences in the effects of stress on the self-other distinction. Psych neuroendocrinology, 43, 95-104.

[37] Mcdonough, P, \& Walters, V (2001). Gender and health: Reassessing patterns and explanations. Social Science \& Medicine, 52, 547-559.

[38] Vermeulen, M, \&Mustard, C (2000). Gender differences in job strain, social support at work, and psychological distress. Journal of Occupational Health Psychology, 5, 428-440.

[39] Roxburgh, S (1996). Gender differences in work and well-being: Effects of exposure and vulnerability. Journal of Health and Social Behavior, 37, 265-277.

[40] Lazarus, RS (2006). Stress and emotion: a new synthesis. New York: Springer Publishing Company.

[41] Essen. LV, Norberg. AL, Pôder. UL, (2011), Early avoidance of disease- and treatment-related distress predicts post-traumatic stress in parents of children with cancer. European Journal of Oncology Nursing.

[42] Cabizuca M, Mendlowicz, M, Marques-Portella C., Ragoni C., Coutinho E., Wanderson K., Mari J, Figueira I.,(2010) The invisible patients: posttraumatic stress disorder in parents of individuals with cystic fibrosis. Rev Psiq Clín.; 37(1):6-11

[43] Famularo R, Fenton T, Kinscherff R, Augustyn M. (1996) Psychiatric comorbidity in childhood posttraumatic stress disorder. Child Abuse Negl.; 10:953-61.

[44] Woods SJ, Wineman NM. (2004).Trauma, posttraumatic stress disorder symptom clusters, and physical health symptoms in post abused women. Arch Psychiatr Nurs.; 18(1):26-34.

[45] Libov BG, Nevid JS, Pelcovitz D et al. (2002) Posttraumatic stress symptomatology in mothers of pediatric cancer survivors. Psychology and Health; 17: 501-511.

[46] Landolt MA, Ribi K, Laimbacher J, Vollrath M, Gnehm HE, Sennhauser FH. (2002) Posttraumatic stress disorder in parents of children with newly diagnosed type 1 diabetes. J Pediatr Psychol.; 27: 647-52.

[47] Landolt MA, Vollrath M, Laimbacher J, Gnehm HE, Sennhauser FH. (2005) A prospective study of posttraumatic stress disorder in parents of children with newly diagnosed type 1 diabetes. J Am Acad Child Adolesc Psychiatry.; 44(7):682-9.

[48] Manne S1, DuHamel K, Ostroff J, Parsons S, Martini DR, Williams SE, Mee L, Sexson S, Austin J, Difede J, Rini C, Redd WH.(2004). Anxiety, depressive, and posttraumatic stress disorders among mothers of pediatric survivors of hematopoietic stem cell transplantation. Pediatrics; 113(6):1700-8. 
[49] Dixon-Woods M, Findlay M, Young B et al. (2001) Parents' accounts of obtaining a diagnosis of childhood cancer. Lancet; 357: 670-674.

[50] McCarthy MC, McNeil, R., Drew, S., Dunt, D., Kosola, S., Orme, L., Sawyer, SM (2016). Psychological Distress and Posttraumatic Stress Symptoms in Adolescents and Young Adults with Cancer and Their Parents. J Adolescent Young Adult Oncology, 5(4):322-329.

[51] Poder U., (2008) Posttraumatic stress among parents of children on cancer treatment: support, care, and distress. Acta Universities Up saliences Uppsala. Digital comprehensive summaries of Acta Universities Uppsala Dissertation from Faculty of Medicine, pp.354 -356. ISSN 1651-6206

[52] Pöder, G. Ljungman, and von Essen L. (2008). Posttraumatic stress disorder among parents of children on cancer treatment: A longitudinal study. Psycho-Oncology. 17(5), 430-437. Retrieved from http://www.ncbi.nlm.nih.gov/pubmed/17847123

[53] Nichole, J. Alanna Long, BA, Luis Ticona, BS, and Sean P,(2009) Symptoms of Posttraumatic Stress in Parents of Children with Cancer: Are they Elevated Relative to Parents of Healthy Children .J Pediatr Psychol.; 34(1): 4-13.

[54] Wong, MY, \& Chan, SW (2006). The qualitative experience of Chinese parents with children diagnosed with cancer. Journal of Clinical Nursing, 15, 710-717.

[55] Patino-Fernandez, AM, Pai, ALH, Alderfer, M, Hwang, W-T, Reilly, A, \& Kazak, AE (2008). Acute stress in parents of children newly diagnosed with cancer. Pediatric Blood \& Cancer, 50, 289-292.

[56] Kazak AE, Rourke MT, Alderfer MA et al. (2007) Evidence-based assessment, intervention and psychosocial care in pediatric oncology: a blueprint for comprehensive services across treatment. J Pediatric Psychology; 32: 1099-1110.

[57] Woodgate RL, Degner LF. (2003) A substantive theory of keeping the spirit alive: the spirit within children with cancer and their families. J Pediatric Oncology Nursing; 20: 103-119.

[58] von Essen L, Enskär K, Skolin I.(2001) Important aspects of care and assistance for parents of children, 0-18 years of age, on or off treatment for cancer. Parent and nurse perceptions. Eur J Oncol Nurs; 5:

[59] Shields L, Hunter J, Hall J. (2004) Parents' and staff's perceptions of parental needs during a child's admission to hospital: an English perspective. J Child Health Care; 8: 9-33.
[60] Pöder, U, Ljungman, G, \& Von Essen, L (2010). Parents' perceptions of their children's cancer-related symptoms during treatment: A prospective, longitudinal study. Journal of Pain and Symptom Management, 40, 661-670.

[61] Alkhateeb, S., (1987) Female Employment And Family Commitment In Saudi Arabia. A Case Study of Riyadh City. A Dissertation Presented to Social Anthropoloy Department, University College London. Doctor of Philosophy

[62] Ångström-Brännström, C, Norberg, A, Strandberg, G, Söderberg, A, \& Dahlqvist, V (2010). Parents' experiences of what comforts them when their child is suffering fromcancer. Journal of Pediatric Oncology Nursing, 27, $266-275$.

[63] Keane TM, Marshall AD, Taft CT. (2006) Posttraumatic stress disorder: etiology, epidemiology, and treatment outcome. Annu Rev Clin Psychol; 2: 161-197.

[64] Yalug I, Corapcioglu F, Fayda M et al. (2008) Posttraumatic stress disorder and risk factors in parents of children with a cancer diagnosis. Pediatric Hematolo

[65] Jurbergs N, Long A, Ticona L et al. (2007) Symptoms of posttraumatic stress in parents of children with cancer: are they elevated relative to parents of healthy children? J Pediatric Psychology; E-pub ahead of print, DOI:10.1093/jpepsy/jsm119.

[66] Manne S, DuHamel K, Redd WH. (2000) Association of psychological vulnerability factors to posttraumatic stress symptomatology in mothers of pediatric cancer survivors. Psych-oncology; 9: 372- 384.

[67] Manne S, Du Hamel K, Gallelli K et al. (1998) Posttraumatic stress disorder among mothers of pediatric cancer survivors: diagnosis, comorbidity, and utility of the PTSD checklist as a screening instrument. Pediatric Psychology; 23: 357-366.

[68] Nakajima-Yamaguchi R, Morita N, Nakao T, Shimizu T., Yasukazu Ogai Y., Takahashi H Saito T., Nakatani Y and Fukushima T.,(2016) Parental Post-Traumatic Stress Symptoms as Predictors of Psychosocial Problems in Children Treated for Cancer Int. J. Environ. Res. Public Health, 13(8), 812; doi: 10.3390/ijerph13080812.

[69] Rechenberg K, Grey M.,\& Sadler L.,(2017) Stress and Posttraumatic Stress in Mothers of Children With Type 1 Diabetes, Journal of Family - journals.sagepub.com Retrieved from

http://link.springer.com/article/10.1007\%2Fs00467-015-3294 $-0$ 